\title{
Quantitative Mass Spectrometry for Bacterial Protein Toxins - A Sensitive, Specific, High-Throughput Tool for Detection and Diagnosis
}

\author{
Anne E. Boyer ${ }^{1}$, Maribel Gallegos-Candela ${ }^{1}$, Renato C. Lins ${ }^{2}$, Zsuzsanna Kuklenyik ${ }^{1}$, Adrian \\ Woolfitt $^{1}$, Hercules Moura ${ }^{1}$, Suzanne Kalb ${ }^{1}$, Conrad P. Quinn ${ }^{3}$ and John R. Barr ${ }^{1, *}$ \\ 1 Centers for Disease Control and Prevention, 4770 Buford Hwy, NE, Atlanta, GA 30341, USA; \\ E-Mail: aboyer@cdc.gov (A.E.B.) \\ 2 Battelle Analytical Services, Atlanta, at the Centers for Disease Control and Prevention, 4770 \\ Buford Hwy, NE, Atlanta, GA 30341, USA \\ 3 Centers for Disease Control and Prevention, 1600 Clifton Rd., Atlanta, GA 30333, USA \\ * Author to whom correspondence should be addressed; E-Mail: jbarr@cdc.gov; \\ Tel.: +1-770-488-7848; Fax: +1-770-488-0509.
}

Received: 14 February 2011; in revised form: 1 March 2011 / Accepted: 9 March 2011 / Published: 14 March 2011

\begin{abstract}
Matrix-assisted laser-desorption time-of-flight (MALDI-TOF) mass spectrometry (MS) is a valuable high-throughput tool for peptide analysis. Liquid chromatography electrospray ionization (LC-ESI) tandem-MS provides sensitive and specific quantification of small molecules and peptides. The high analytic power of MS coupled with high-specificity substrates is ideally suited for detection and quantification of bacterial enzymatic activities. As specific examples of the MS applications in disease diagnosis and select agent detection, we describe recent advances in the analyses of two high profile protein toxin groups, the Bacillus anthracis toxins and the Clostridium botulinum neurotoxins. The two binary toxins produced by $B$. anthracis consist of protective antigen (PA) which combines with lethal factor (LF) and edema factor (EF), forming lethal toxin and edema toxin respectively. LF is a zinc-dependent endoprotease which hydrolyzes specific proteins involved in inflammation and immunity. EF is an adenylyl cyclase which converts ATP to cyclic-AMP. Toxin-specific enzyme activity for a strategically designed substrate, amplifies reaction products which are detected by MALDI-TOF-MS and LC-ESI-MS/MS. Pre-concentration/purification with toxin specific monoclonal antibodies provides additional specificity. These combined technologies have
\end{abstract}


achieved high specificity, ultrasensitive detection and quantification of the anthrax toxins. We also describe potential applications to diseases of high public health impact, including Clostridium difficile glucosylating toxins and the Bordetella pertussis adenylyl cyclase.

Keywords: Bacillus anthracis; anthrax lethal factor; anthrax edema factor; Clostridium botulinum; neurotoxins; mass spectrometry

\section{Introduction}

Bacterial protein toxins are among the most potent natural poisons known. Members of this group of bioactive polypeptides can cause irreversible changes to host cellular targets resulting in a wide variety of functional losses, ranging from the paralyses caused by clostridial neurotoxins (flaccid paralysis or tonic spasms), to the immune collapse, endothelial dysfunction, hemorrhage and death due to the anthrax toxins [1,2]. Quantitative detection of specific toxin activity in clinical samples yields insights into the kinetics of intoxication, stage of infection, and pathogenesis associated with the presence and quantity of certain toxins. Rapid high-throughput analysis also has the potential to provide measurements that quantify the efficacy of toxin-based therapeutics and support patient management decisions during treatment. Methods recently developed in our laboratory have targeted the seven Clostridium botulinum neurotoxin types A-G and subtypes [3-5], and the Bacillus anthracis binary toxins $[2,6,7]$.

The seven structurally related C. botulinum neurotoxin proteins (BoNTs) intoxicate the peripheral nervous system where they inhibit calcium-dependent secretion of acetylcholine at the neuromuscular junction and cause flaccid paralysis. The BoNTs are released from C. botulinum as single chain polypeptides that are post-translationally modified by protease hydrolysis to form covalently linked dichain polypeptides, each with three discrete structural and functional domains. The common architecture of the BoNTs comprises an enzymatically active light chain (LC, $50 \mathrm{kDa}$ ) linked via a disulfide bridge to a receptor binding and translocating heavy chain $(\mathrm{HC}, 100 \mathrm{kDa})$. The $\mathrm{HC}$ is further comprised of two regions; the amino terminal $50 \mathrm{kDa}\left(\mathrm{H}_{\mathrm{N}}\right)$ domain with a translocation function and a $50 \mathrm{kDa}$ carboxyl terminal $50 \mathrm{kDa}$ domain $\left(\mathrm{H}_{\mathrm{C}}\right)$. The $\mathrm{LC}$ domains contain a zinc-dependent endoprotease activity which target one or more of the three membrane proteins involved in presynaptic cell secretory vesicle docking and membrane fusion, thus preventing neurotransmitter release. BoNTs /A, /C and /E hydrolyze synaptosomal associated protein 25 (SNAP-25), BoNTs B, D, F and G hydrolyze isoforms of synaptobrevin, also known as vesicle associated membrane protein (VAMP-2). $\mathrm{BoNT} / \mathrm{C}$ is unique within the group in that it also hydrolyzes a second substrate, syntaxin, in the vesicle docking complex [8].

The seven BoNT serotypes A-G have considerable sequence diversity as well as regions of homology between toxin types. In addition, several toxin subtypes have been described for each toxin type [9]. As described, the active BoNT consists of both the HC responsible for binding the cellular receptor and translocating the $\mathrm{LC}$ that carries the endoproteolytic activity [10]. At the extremes in diversity are the BoNT/C and BoNT/D toxins which have combined through evolution to form mosaic toxins that are mixtures of type /C and type /D neurotoxins [11]. Extensive characterization of these 
toxins has revealed that these mosaic toxins are either consistent with a type /C heavy chain and /D light chain, or a /D heavy chain and /C light chain [12]. Differentiation of the toxin type is clinically critical for ensuring treatment with the appropriate anti-toxin $[5,13]$.

Bacillus anthracis is a Gram positive spore-forming rod. Exposure to the spores typically occurs via three routes: 1) dermal contact results in cutaneous anthrax, 2) ingestion results in gastrointestinal anthrax, and 3) inhalation results in the most deadly form, pulmonary anthrax. When spores enter the body, they germinate, enter the vegetative growth phase and begin to produce toxin. The anthrax toxins are secreted as three distinct proteins and their activities have been well described $[14,15]$. Protective antigen (PA) is secreted as an $83 \mathrm{kDa}$ protein that binds to cell surface receptors and is cleaved by furin-like protease releasing a $20 \mathrm{kDa}$ portion and retaining the $63 \mathrm{kDa}$ form at the cell surface $\left(\mathrm{PA}_{63}\right)$ [16,17]. $\mathrm{PA}_{63}$ forms an oligomer comprising up to 8 molecules of $\mathrm{PA}_{63}$ and is responsible for toxin internalization [18]. It combines with lethal factor (LF) and edema factor (EF), forming lethal toxin (LTx) and edema toxin (ETx) respectively [14] (Figure 1). LF is similar to the BoNT's in that it is a zinc-dependent endoprotease. The substrate for LF hydrolysis however, is the mitogen activated protein kinase kinase (MAPKK) family of response regulators centrally involved in inflammation and immunity [15]. EF is a calmodulin-dependent adenylyl cyclase that converts ATP to cyclic AMP (cAMP). Elevated cAMP leads to edema and immune suppression. Both toxins synergize to cause immune dysregulation, endothelial dysfunction, advanced septicemia, hemorrhage, and shock which often leads to death [19,20].

Figure 1. Bacillus anthracis secretes three toxin-associated proteins, lethal factor (LF), protective antigen (PA), and edema factor $(\mathrm{EF})$ which form the two binary anthrax toxins. Protective antigen $\left(\mathrm{PA}_{83}\right)$ is an $83 \mathrm{kDa}$ protein responsible for toxin entry into the cell. PA binds receptors at the cell surface where it is cleaved by a furin-like protease removing a $20 \mathrm{kDa}$ portion. The remaining $63 \mathrm{kDa} \mathrm{PA}_{63}$ forms an oligomer at the cell surface that binds three molecules of lethal factor (LF), a zinc-endopeptidase, and edema factor (EF), adenylyl cyclase, forming lethal toxin and edema toxin respectively.

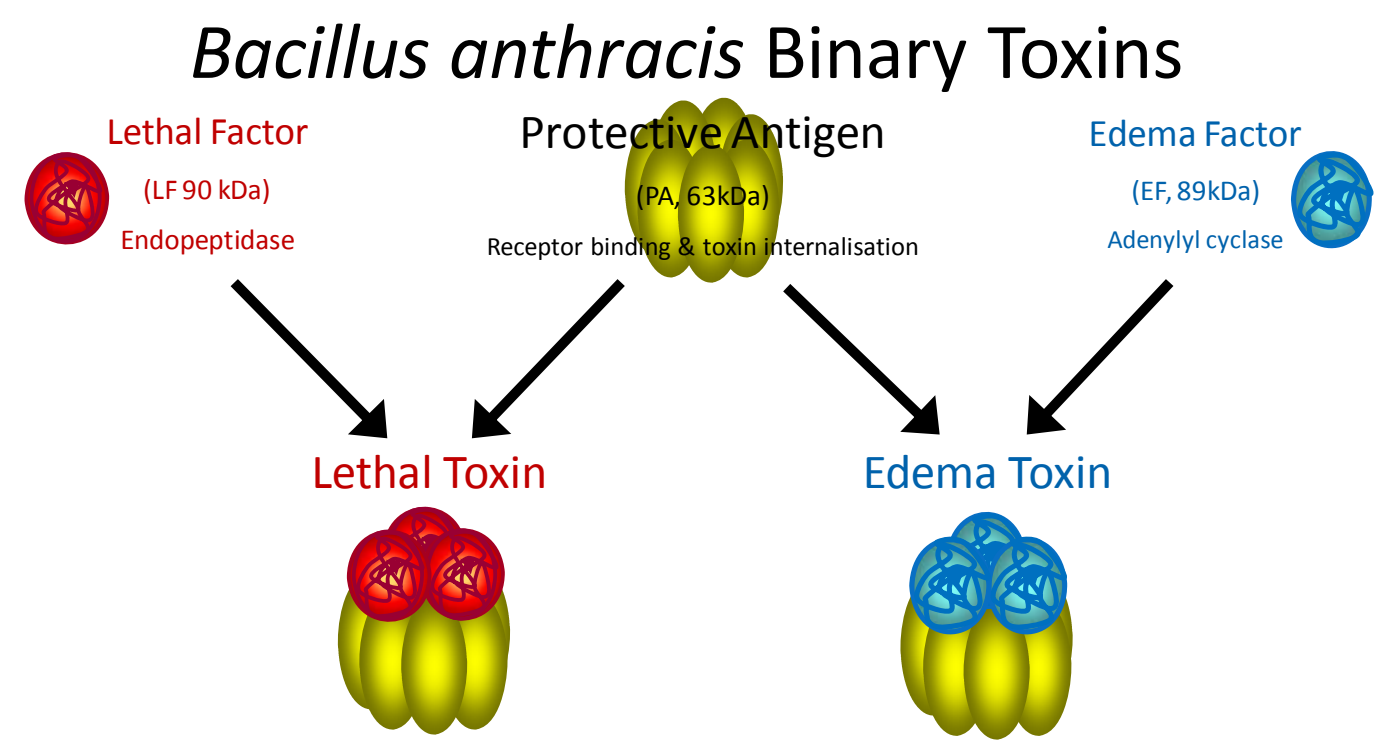

Our work has exploited customized peptide substrates that enable accumulation of stable peptide hydrolysis products for MS detection. This accumulation serves to amplify the reporter signal capacity 
of the enzymatic activities of specific toxins. Combined with MS detection, the result is an analytically ultra-sensitive method (attomoles/mL) for detection and quantification of toxin activities in clinical samples. Toxin-activity targeted quantification has many benefits. The first is the capacity for amplification and increased sensitivity with specific toxin selection. Rather than detecting molecular levels of a substance, protein, or enzyme toxin in the blood, detecting the toxins activity in the presence of excess substrate allows accumulation of the enzyme-specific reaction products over time. Furthermore, detection of toxin-specific reaction products may often be easier and simpler than detection of the toxin itself. An additional benefit to the toxin-activity/analytical detection approach includes substrate selection. The substrate may be strategically designed to enhance both activity and analytical detection of the resulting reaction products. Also, selecting toxins over other molecular diagnostic targets may be important since toxin activities are often clinically and pathologically relevant. This was demonstrated for the anthrax toxin LF levels that were inversely associated with survival time during experimental inhalation anthrax [21]. In addition, the exotoxins are secreted factors that do not remain associated with the microorganisms. For example, targeting the toxin is essential for detecting botulism, because it is generally a consequence of ingesting or adsorbing preformed toxin and is not usually the result of an infection, except for infant and adult colonization botulism. For anthrax and other infections, toxin detection is important because of the potential for antimicrobial or immunological clearance of the organism, which was shown to occur during experimental inhalation anthrax [6] and in clinical inhalation anthrax [22]. In human inhalation anthrax, LF was not cleared and remained detectable in the blood for 12 days after antimicrobial treatment [22]. During experimental anthrax infection, diagnostic tests that depended on detection of the organism (culture) or its DNA (PCR) were negative within 24 hours after the initiation of antimicrobial therapy [21]. Additionally, secreted toxins are often produced at high levels during infection and therefore, may accumulate in blood or other clinical samples. LF was detected in the blood of rhesus macaques as early as 12 hours after inhalation exposure to B. anthracis Ames spores [21]. Depending on the route of infection or intoxication, toxins are often the most viable, relevant, and abundant target.

Analytical MS-based detection is one of the important features of these toxin activity/reaction product targeted methods. MS is unique in that it provides additional assurance of specificity compared to ELISA colorimetric or fluorescent assays which sometimes exhibit cross reactivity [23]. Our methods for toxin activity quantification by MS incorporate three levels of specificity and sensitivity that provide unparalleled diagnostic assurance. The three levels include 1) toxin purification/ enrichment using monoclonal antibodies (mAbs) specific for the toxin that are covalently bound to magnetic beads, 2) toxin-specific enzyme activity directed against a specific substrate, and 3) mass specific detection of the toxin-generated reaction products. This method schematic is shown for MS detection of the anthrax toxins, LF and EF (Figure 2). LF and EF are found in the blood as both the monomers LF and EF and in complex with $\mathrm{PA}_{63}$ as LTx [24,25] and ETx, respectively. Therefore methods are developed using monoclonal antibodies that can capture both forms of LF and EF and include the total LF $(\mathrm{LF}+\mathrm{LTx})$ and total EF $(\mathrm{EF}+\mathrm{ETx})$. Briefly, the total LF is captured from a clinical sample using LF-specific monoclonal antibodies bound to magnetic beads (Figure 2A). The captured LF is then exposed to a MAPKK-like peptide substrate that it hydrolyzes at a specific residue yielding two products of a specific mass. The remaining substrate and two LF-specific products are detected by MALDI-TOF MS (Figure 2A). The same method flow has been followed to develop 
quantitative methods for EF adenylyl cyclase activity using the LC-ESI-MS/MS platform, which is preferred for detection of the small molecules represented by EF's substrate ATP and catalytic product cAMP (Figure 2B).

Figure 2. Schematic for total LF (LF+LTx) (A) and total EF (EF+ETx) detection by mass spectrometry. LF is captured by monoclonal antibodies (mAbs), mixed with a synthetic peptide substrate that is hydrolyzed, then the remaining substrate and two hydrolysis products are detected by MALDI-TOF MS. EF is captured by mAbs, then incubated with ATP and the adenylyl cyclase cofactor calmodulin, then ATP and the adenylyl cyclase reaction product cAMP are detected by LC-ESI-MS/MS.

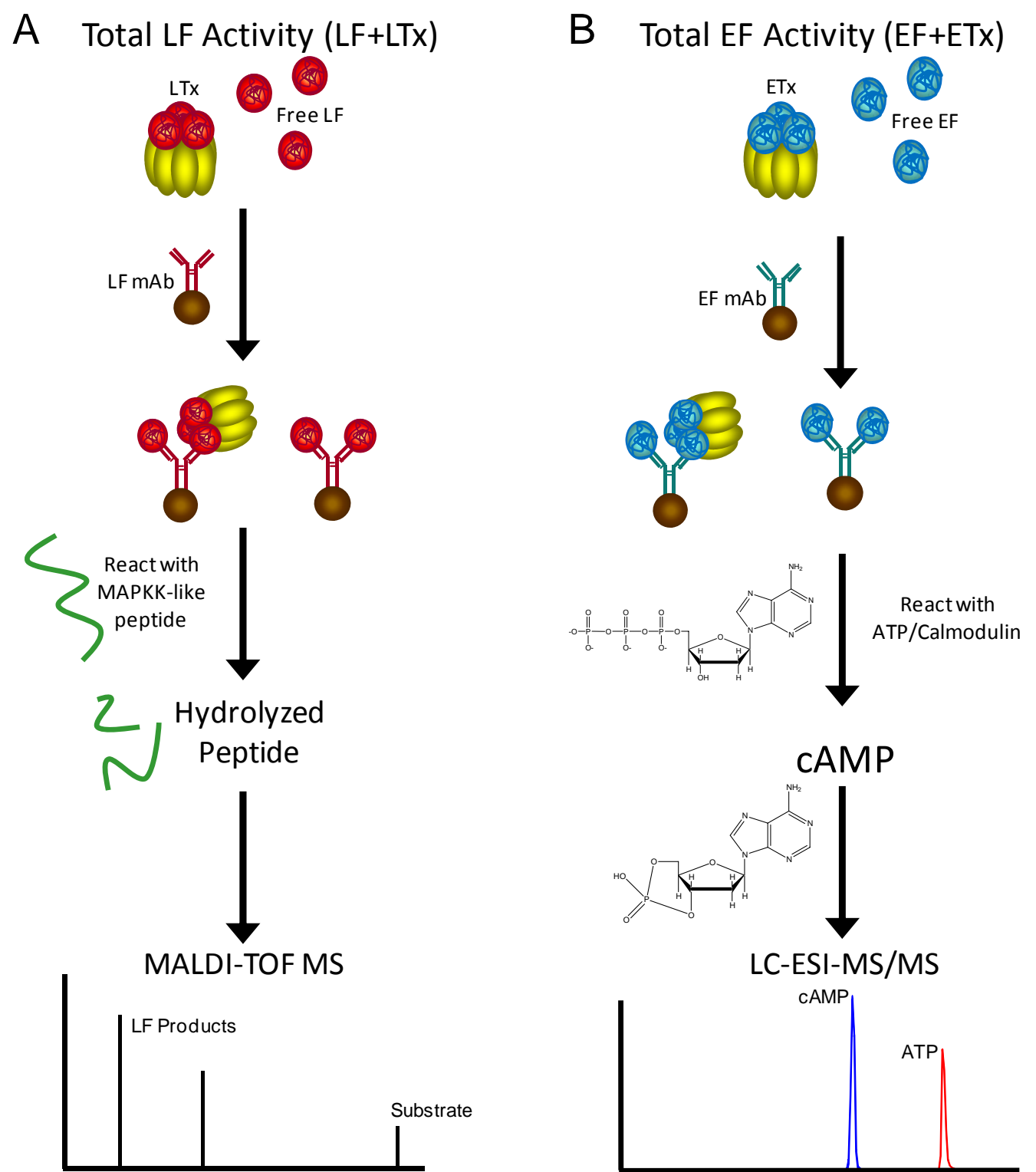

\section{Mass Spectrometric Detection of Toxin Activity}

\subsection{MALDI-TOF MS for peptides}

Detection of the activity of endoproteolytic toxins such as the botulinum neurotoxins and LF is typically performed by MALDI-TOF MS because it is high-throughput (analyzes a 384-spot plate in 
less than 45 minutes), sensitive and robust. After the endoprotease peptide substrate cleavage reaction, no sample purification is needed. Samples are mixed with a chemical matrix consisting of $\alpha$-cyano-4hydroxycinnamic acid (CHCA) and spotted on the plate where it co-crystallizes with the sample. A $337 \mathrm{~nm}$ nitrogen laser strikes the chemical matrix containing sample on each spot. This ionizes and desorbs the peptides from the plate (laser desorption ionization) and a voltage potential is applied that propels the ions down a flight tube where they are separated by mass-to-charge $(\mathrm{m} / \mathrm{z})$ ratio (time-offlight). Since all ions have the same energy, peptide ions with a smaller $\mathrm{m} / \mathrm{z}$ ratio travel faster and are first to the detector, while ions with larger $m / z$ ratio are slower $\left(E=m v^{2}\right)$. The instrument calibration accounts for these differences in $\mathrm{m} / \mathrm{z}$ ratios with mass calibration standards. The spectra are high resolution $(10,000-14,000)$ and the isotopic distributions associated with each peptide are distinct, easily visible, and can be observed in subsequent figures. MALDI-TOF MS is highly sensitive and often detects peptides less than $4,000 \mathrm{~m} / \mathrm{z}$ in the femtomolar range. The high sensitivity of product detection is important because some toxins, such as BoNTs, are highly potent and very little is required to produce fully-paralytic botulism. MALDI-TOF MS also allows very early detection of the anthrax toxins, within 12-24 h after exposure to spores, when toxin levels are still quite low. In addition, the MALDI-TOF MS method for anthrax toxins are fast, providing results in less than 4 hours, and highthroughput, analysis of a 384-spot MALDI plate can be completed in less than 45 minutes. As observed in the 2001 anthrax letter attacks, the fatality rate was $45 \%$ despite the use of antibiotics and aggressive supportive care [22]. Early detection is essential for improving survival with conventional treatment. The sensitive, fast, MS-based toxin methods may provide the early diagnosis required for increasing survival rates.

A simple MALDI-TOF MS method for scanning masses in the appropriate mass range can visualize differences in toxin substrate reactivity, reaction mixture components, and antibody capture optimization. MALDI-TOF MS delivers a MS fingerprint of most peptides in a mixture. Thus, it can easily visualize substrate hydrolysis as well as the introduction of potential interferences during method development. This is shown for a simple reaction without and with LF added to reaction buffer with a synthetic peptide substrate, designed as an enhanced surrogate to its natural MAPKK substrate (Figure 3). The sequence of the peptide substrate (LF-5) has an expected mass of 2,804.2 $\mathrm{m} / \mathrm{z}$. Cleavage of LF-5 by LF would yield two smaller product peptides of expected masses: amino terminal product (NT5) of $1,231.8 \mathrm{~m} / \mathrm{z}$ and carboxy terminal product (CT5) of 1,589.8 m/z (Figure 3A). MALDI-TOF MS for pure reactions (in the absence of a sample matrix such as serum and without antibody purification) was very clear. In the absence of LF, the full mass spectrum shows that only the singly and doubly charged substrate peaks are present (Figure 3B). In the presence of $1 \mathrm{ng}$ LF, the substrate peak is reduced and two LF-specific product peaks of the expected masses are present (Figure 3C).

In addition to assessing adequate substrate hydrolysis under perfect conditions without sample interferences, the mass specificity and total fingerprint view of the catalytic reaction mixture allows MALDI-TOF MS to assess potential cross reactivity. For clinical samples, the abundance of proteases in serum and other clinical matrices may cause non-specific substrate degradation, yielding many smaller peptide products of different masses. MALDI-TOF MS readily detects this type of nonspecific peptide hydrolysis. Figure 3D depicts a MALDI-TOF MS of a whole blood (WB) negative control (without LF) after purification by LF mAbs on magnetic beads and incubation with LF5 by 
methods described previously [6,7]. The spectrum shows many peaks associated with non-specific protease activity (Figure 3D). However, in WB containing $0.1 \mathrm{ng}$ LF, cleavage of LF5 yields the LFspecific product peaks at $1,232.8$ and $1,589.8 \mathrm{~m} / \mathrm{z}$, in addition to the non-specific peaks which are reduced due to abundant LF-specific cleavage (Figure 3E). Narrowing the $\mathrm{m} / \mathrm{z}$ range allows visualization of the CT5-associated peak which is minimal in WB without LF and has high peak intensity in WB spiked with LF (Figures 3D, E). Our combination of procedures for detection of LF and BoNT activity are optimized to eliminate residual protease activity and are described below. Figure 3 shows that even under the most extreme conditions, MS provides reliable specificity and detects the difference between samples containing LF and those without LF, effectively ruling out nonspecific cleavage.

Figure 3. Specificity of MALDI-TOF MS detection of LF hydrolytic activity. Amino acid sequence and expected mass/charge $(\mathrm{m} / \mathrm{z})$ of lethal factor $(\mathrm{LF})$ endoproteolytic MAPKKlike substrate (LF-5) and LF-specific hydrolysis products; amino-terminal product (NT5) and carboxy-terminal product (CT5) (A). MALDI-TOF MS of 2 nmoles LF-5 substrate and reaction buffer without LF (B) and with $1 \mathrm{ng}$ LF (C). Both reactions, with and without LF, were incubated for 2 hours at $37{ }^{\circ} \mathrm{C}$, and analyzed by MALDI-TOF MS scanning from 1,000-3,000 m/z. MALDI-TOF MS of $200 \mu \mathrm{L}$ whole blood without LF (WB blank) (D) and spiked with $0.5 \mathrm{ng} / \mathrm{mL}$ LF (E) and purified with LF mAbs covalently bound to tosylactivated magnetic beads, incubated overnight in a reaction buffer containing 2 nmoles substrate. Narrowing the $\mathrm{m} / \mathrm{z}$ range on the CT5 $(\mathrm{m} / \mathrm{z}$ 1,589.8) product shows the specificity for LF cleavage without LF (D) and with LF (E). Signal intensity for the CT5 focused mass window for WB blank was normalized to the focused spectrum for the $0.5 \mathrm{ng} / \mathrm{mL} \mathrm{LF}$ spiked in WB.

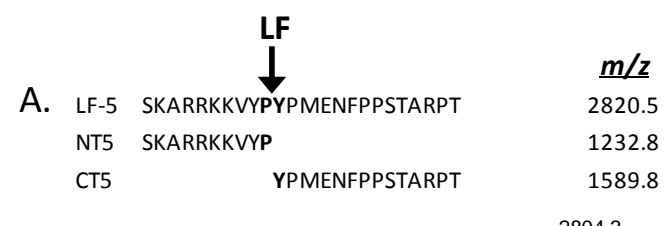

B.

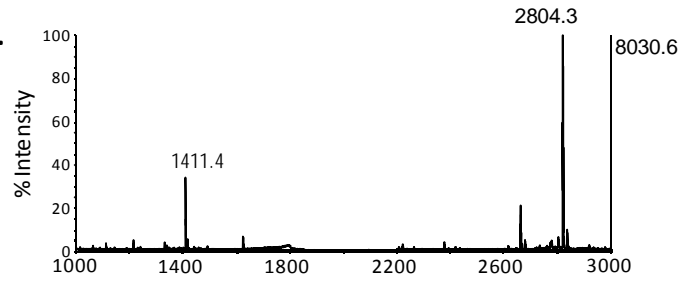

D.
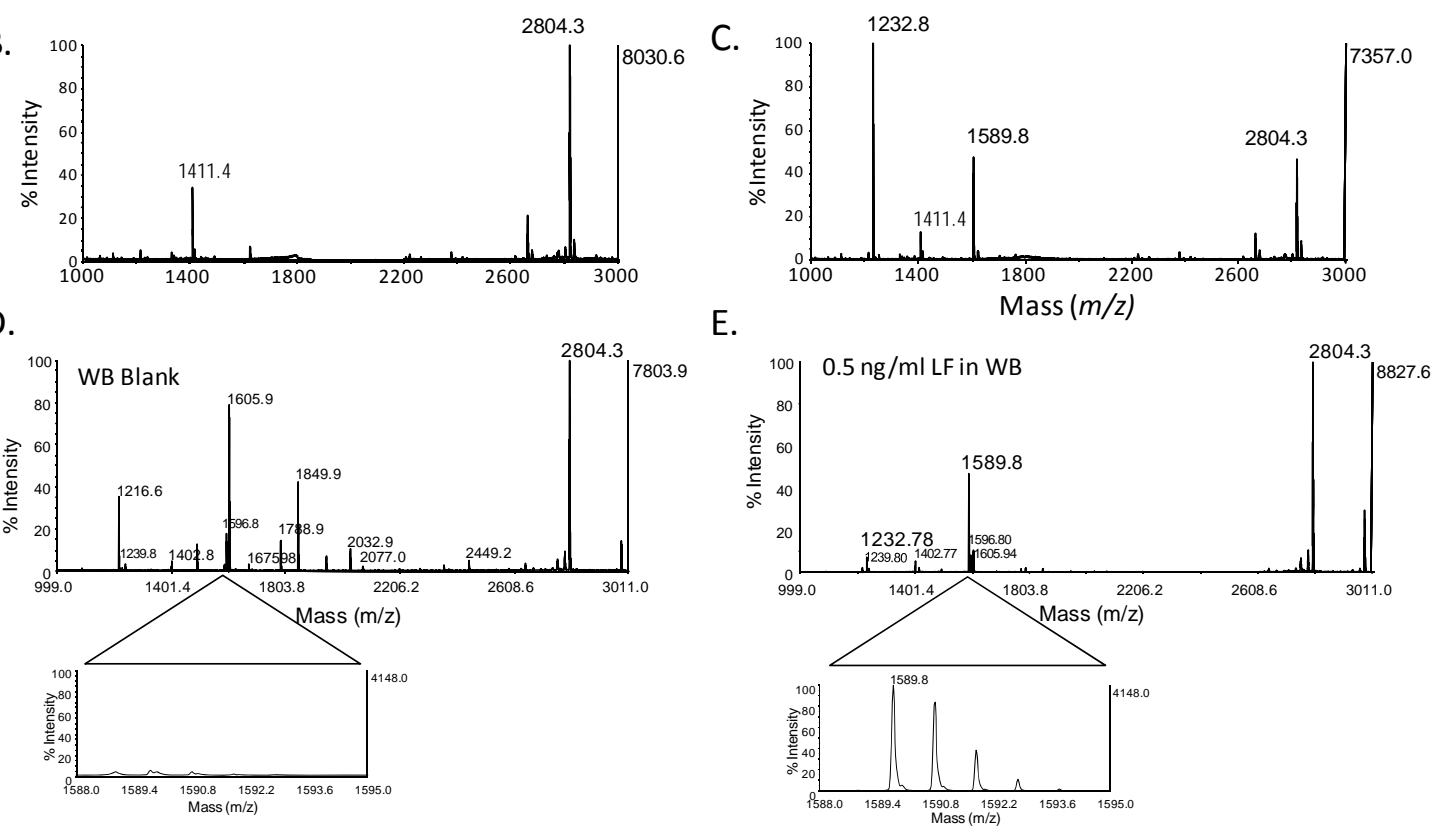


\subsection{Isotope dilution quantification for MALDI-TOF MS}

Isotope dilution refers to the inclusion of an isotopically labeled, synthesized version of the target analyte with the sample for analysis. It serves as an internal standard (IS) to account for potential error related to sample processing and analysis. Isotope dilution improves the accuracy and precision of MS based quantification and is particularly important for MALDI-TOF MS quantification methods because of the co-crystallization process, for which stable isotope labeled internal standards cocrystallize with the native analytes. It has previously been described in detail for tandem MS (MS/MS) quantification [26,27]. In the case of LF activity, for the substrate LF4, the two internal standards are synthetic peptides, NT4-IS and CT4-IS, which each contain an isotopically labeled alanine (+7 mass units; with ${ }^{13} \mathrm{C}_{3},{ }^{15} \mathrm{~N}, \mathrm{D}_{3}$ ) incorporated in place of the unlabeled alanine (Table 1). The IS sequences match those of the LF cleavage products, NT4 and CT4 (Table 1).

Table 1. The eight known LF protein targets aligned by their previously deduced cleavage sites. The floating consensus shown is based on the one or two most abundant amino acids at a position. LF hydrolyzes these sequences between the $\mathrm{P} 1$ and $\mathrm{P} 1$ ' residues (in bold print). MAPKK sequences for M1 (P29678), M2 (P36506), M3 (P46734), M4a and M4b (P47809), M6 (P52564), and M7a and M7b (O14733) from the National Center for Biotechnology Information (www.ncbi.nlm.nih.gov). LF-1 is a synthetic peptide based on the FRET-based substrate with enhanced cleavage compared to MAPKK-1 identified by Turk et al [30]. The core of LF-1 in parentheses is used for designing longer substrates, LF-2 to LF-4 and LF-S. Substrate and internal standard (IS) peptide sequences and [M + $\mathrm{H}]^{+}$masses are listed.

\begin{tabular}{|c|c|c|c|c|}
\hline Name & & Seque & ence & $\lfloor\mathbf{M}+\mathbf{H}\rfloor^{+}$ \\
\hline & & $\mathbf{P 1} \downarrow$ & P1' & \\
\hline MAPKK-1 $1_{1-25}$ & (M1) & MP K K K P T P & I QLNPAP DGS AVNGTS S & \\
\hline MAPKK-2 $2_{1-27}$ & (M2) & M LAR R K P V L P & ALT INPT I AEGPSPTS E & \\
\hline MAPKK-3b $b_{17-43}$ & (M3) & G K S KR K K DL R & I S C MS KP P AP NP T P P R N & \\
\hline MAPKK-4 $36-62$ & (M4a) & S MQ GKR KA L K & L NF ANP P F KS T ARF T L N & \\
\hline MAPKK-4 $49-75$ & $(\mathrm{M} 4 \mathrm{~b})$ & ANP P F KS T A R & F T L NP NP T GVQNP H I E R & \\
\hline MAPKK-6 $6_{5-31}$ & (M6) & K GKKR N P GL K & I P KE AF E QP QTS S T P P R & \\
\hline MAPKK-7 $35-61$ & (M7a) & S P Q R P R P T L Q & L P L ANDGGS R P S S ES S & \\
\hline MAPKK-7 $67-93$ & (M7b) & P P A R P R HM L G & LPS T L F T P R S MES IE I D & \\
\hline Consensus & & S P AR R KKT L ${ }^{p / K}$ & $\mathrm{~L} / \mathrm{P}$ L N/A $/ \mathrm{N}_{\mathrm{P}}^{\mathrm{p} / \mathrm{F}} / \mathrm{p} / \mathrm{P}$ A S T P S P T S & \\
\hline LF-1 (Core) & & (R R K K VY P & Y P ME) PT I A & 1751.9 \\
\hline LF-2 & & R R K K V Y P & Y P ME PT I AK & 1880.1 \\
\hline LF-3 & & S P ARR KKVY P & Y P ME NP T P R S T P S P T & 2857.5 \\
\hline LF-4 & & S KARRKKVY P & Y P ME NF P P S T AR P T & 2821.5 \\
\hline LF-5 & & S KARR KKVY P & Y P X E NF P P S T ARP T & 2804.2 \\
\hline NT4/5 & & S K AR R K K VY P & & 1232.8 \\
\hline CT4 & & & Y P ME NF P P S T AR P T & 1607.8 \\
\hline NT4/5-IS & & K (A+7) R R K K VY P & & 1239.8 \\
\hline CT4-IS & & & Y P ME NF P P S T $(\mathrm{A}+7)$ R P T & 1614.8 \\
\hline CT5 & & & Y P X E NF P P S T ARP T & 1589.8 \\
\hline CT5-IS & & & Y P X E NF P P S T $(\mathrm{A}+7)$ R P T & 1596.8 \\
\hline
\end{tabular}


For MALDI-TOF MS quantification, each sample reaction mixture with IS is spotted on the MALDI plate with a minimum of three replicates and analyzed. With MALDI-TOF MS, considerable signal-to-signal variation in intensities occurs from spot-to-spot for the same sample mixture. Isotope dilution quantification is effective at normalizing these differences in spectrum intensities. Figure 4A shows the full MALDI-TOF mass spectrum for a cleaved LF substrate NT-4 (Table 1) produced from LF in an archived serum sample from rhesus macaques with inhalation anthrax infection [7]. Narrowing the mass range allows visualization of the target CT4 cleavage product and corresponding C-terminal internal standard (CT4-IS) (7 mass units higher than CT4) for three spectra acquired from individual spots from the same sample (Figure 4B). The intensity of the target analyte at 1,607.8 varies from 8,093 to 13,000 . However, the ratios of the areas of the CT4/CT4-IS are similar. These differences were confirmed quantitatively for multiple samples containing different amounts of LF. Wide variation in the isotopic clustal areas of the CTP was observed for three replicates from the same samples prior to isotope dilution (Figure 4C). However, variation was minimized for the same three spots using the area ratio of the CT4/CT4-IS for normalization (Figure 4D).

Figure 4. Isotope dilution for MALDI-TOF MS. Isotopically labeled internal standard peptides NT4-IS and CT4-IS, 7 mass units higher than the NT4 and CT4 peptide products are added to the sample and mixed in the MALDI chemical matrix CHCA as described previously [7]. A full spectrum is shown for a sample from an experimental rhesus macaque infection (A). The $\mathrm{m} / \mathrm{z}$ range is narrowed for spectra from three spots of the same sample showing the CT4 LF cleaved product and the CT4-IS isotopic peaks and shows the variation in peak intensity from 8,092, 10,000 and 13,000 for the three spots (B). The CT4 peak areas alone were plotted for 10 archived samples from rhesus macaque anthrax inhalation infections and show the variation in area for triplet peaks from the same sample (C). The area ratios, area of CT4 divided by the area of CT4-IS, were plotted for the same 10 samples in $\mathrm{C}$ and shows how the variation was normalized (D). The areas and area ratios of the three spots in $\mathrm{B}$ were circled in $\mathrm{C}$ and $\mathrm{D}$, respectively.

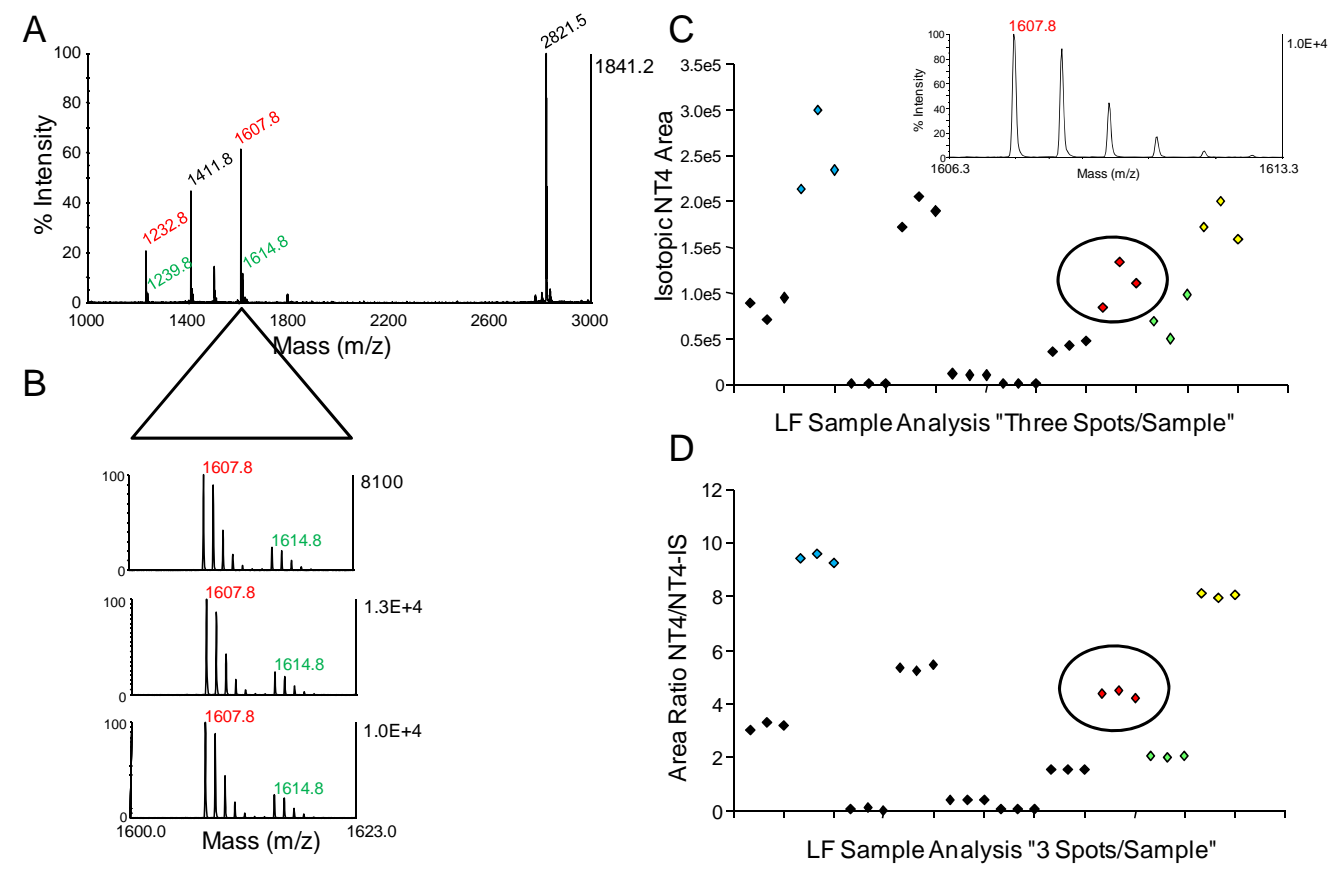




\subsection{LC-ESI-MS/MS for peptides}

LC-ESI tandem MS (MS/MS) is also an appropriate platform for sensitive peptide detection and quantification. It is available in many laboratories and can be used as an alternative to MALDI-TOF MS for most peptide-based methods. In many cases, it is just as sensitive as MALDI-TOF MS and also requires no additional sample purification. One drawback however, is that LC-MS/MS has lower sample throughput. Depending on the optimized LC run conditions a single sample is analyzed in 5-10 minutes rather than in seconds as with MALDI-TOF MS. With MALDI-TOF MS, 96 samples can be analyzed in quadruplicate in less than 45 minutes. For LC-ESI-MS/MS, at least one hour is required to analyze 10 samples.

We further verified the use of MALDI-TOF MS for isotope dilution quantification by validating the LF method on the LC-ESI-MS/MS platform for potential application to public health laboratories housing this equipment, and reported the cross validation between the use of MALDI-TOF MS and LC-ESI-MS/MS for LF activity quantification [28]. We found that detection limits, accuracy and precision were very similar between the two methods. Importantly, we found a very close agreement between quantification of LF in the serum of New Zealand White rabbits with inhalation anthrax. Concentrations measured by ESI-MS/MS correlated with those by MALDI-TOF MS with a Pearson correlation coefficient of $p=0.99$ and $9 \%$ mean difference, verifying the accuracy and interchangeability of both MS platforms for LF activity [28].

Figure 5. The structures of the edema factor (EF) substrate adenosine triphosphate (ATP) and reaction product cyclic adenosine monophosphate (cAMP) (A). Chromatogram for a $2 \mathrm{~h}$ reaction with $2 \mathrm{ng}$ EF in the presence of $1 \mathrm{mM}$ ATP generated by LC-ESI-MS/MS in positive ion mode, for the 508 ATP ion and 329/136 cAMP precursor/product (B).
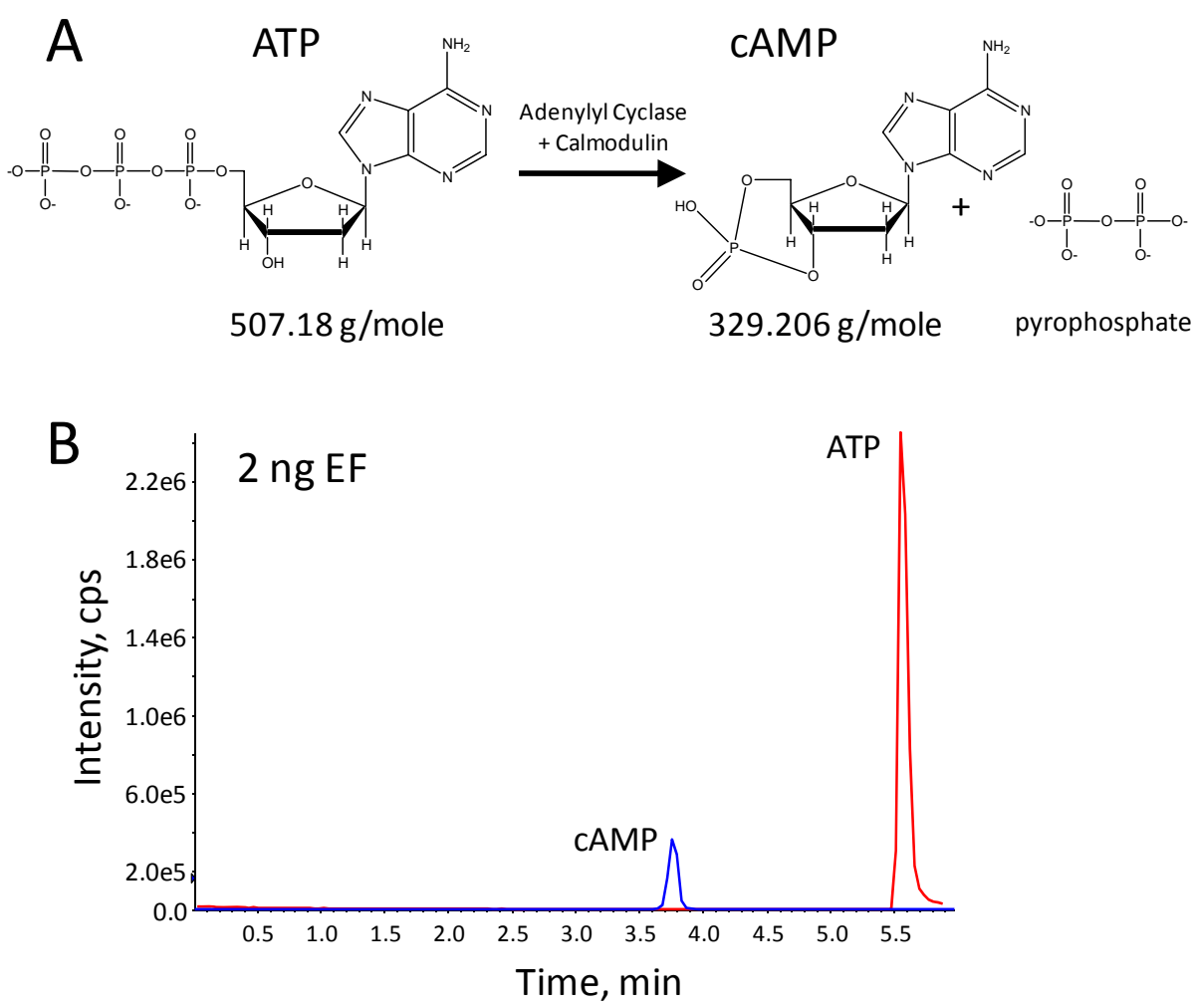


\subsection{LC-ESI-MS/MS for small molecules}

MALDI-TOF MS is sometimes not appropriate for small molecule detection due to interferences from the chemical matrix at masses below $500 \mathrm{~m} / \mathrm{z}$. Therefore, LC-ESI-MS/MS is preferred for MS detection of the low mass substrate and products resulting from enzyme activities of the EF and the Bordetella pertussis adenylyl cyclase (PAC) toxins. In the presence of the cofactors calmodulin and calcium, EF and PAC convert adenosine triphosphate (ATP) to cyclic adenosine monophosphate (cAMP) (Figure 5A). The EF or PAC activity can be measured by the specific conversion of ATP to cAMP and loss of pyrophosphate. However, unlike the high substrate specificity of LF and the BoNTs, there are adenylyl cyclases active in mammalian cell processes. Therefore, specificity is obtained using a prior antibody purification step specific for EF or PAC (Figure 2B).

Optimized separation and detection of ATP, cAMP (Figure 5A) and internal standard 2-chlorocAMP was achieved using a Biobasic AX weak anion exchange HPLC column with 90-20\% acetonitrile and $\mathrm{pH}$ 6.5-10 eluent gradient and a 6 min run time as described previously [29]. Multiple reaction monitoring in positive ESI mode for cAMP included the $329 \mathrm{~m} / \mathrm{z}$ precursor ion and its 136, 312 and $232 \mathrm{~m} / \mathrm{z}$ products, for the 2-chloro-cAMP internal standard the $345 \mathrm{~m} / \mathrm{z}$ precursor ion and its 146,327 and $247 \mathrm{~m} / \mathrm{z}$ products, and for ATP the $508 \mathrm{~m} / \mathrm{z}$ precursor and its $136 \mathrm{~m} / \mathrm{z}$ product was monitored. As optimized, cAMP eluted at $3.8 \mathrm{~min}$ and ATP at 5.6 min (Figure 5B).

\section{Toxin-Specific Substrate Design}

\subsection{Peptide substrate design}

For endoprotease toxins such as botulinum neurotoxin and lethal factor, considerable information regarding known protein substrates is available in the literature [30-33]. LF's known substrates include six family members of the MAPKK's, MAPKK-1, -2, -3, -4, -6, and -7, which it cleaves near the Nterminus [33]. LF was shown to hydrolyze MAPKK-4 and MAPKK-7 in two locations [33]. The Nterminal sequences of the known MAPKK substrates are shown in Table 1. LF cleaves between the P1 and P1' amino acids indicated. Residues at these positions are not strictly conserved among the MAPKK LF substrates, however, they may have certain requirements. For example, the P1 amino acid is more flexible since hydrophobic $(\mathrm{P})$, hydrophilic $(\mathrm{R}, \mathrm{Q})$, amphiphathic $(\mathrm{K})$ and neutral $(\mathrm{G})$ amino acids are represented among the cleavable MAPKK's. The P1' requirements are more stringent, with primarily hydrophobic amino acids (A, I, L, F) represented at this position. Work by Benjamin Turk determined LF cleavage efficiencies for short 9-11 amino acid FRET peptides based on the MAPKK consensus sequence [30]. Applying a degenerate peptide library based approach to the short MAPKK consensus, amino acid substitutions were identified near the cleavage site that enhanced the catalytic efficiency of LF for the short peptide [30]. In the 'enhanced' MAPKK sequence, LF cleavage occurred at the core of a double tyrosine (Y) proline (P) pair (YPYP), cleaving at a P1 proline and atypical P1' tyrosine. This sequence identification provided a means to enhance the catalytic reaction and improved detection limits for our LF MS assay.

In addition to promoting catalytic efficiency in substrate design, certain conserved sequences may need to be maintained. For example, a basic stretch of 2-5 arginines (R) and lysines (K) occur at the Nterminus of all MAPKK's that are LF targets (Table 1). The basic stretch is absent in MAPKK-5 which 
is not cleaved by LF (not shown). In addition, the sequences distal to the cleavage site in MAPKK's contain 2-6 prolines and 2-6 serines and/or threonines (Table 1). Our LF substrate was designed with the YPYP core and maintained these MAPKK derived consensus sequences (LF-3 and LF-4).

We previously investigated the ability of LF to cleave a series of peptide substrates [7]. One was a short peptide based on Turk's enhanced FRET substrate without the donor/quencher FRET pair (LF-1) (Table 1). However, one drawback to LF-1 is that it lacks an ionizable amino acid in the potential LFcleaved C-terminal (CT) product. Therefore, only the N-terminal (NT) LF cleavage product would be ionized and visible by MALDI-TOF MS. To produce a comparable substrate with two visible cleavage products, the second substrate (LF-2) contained an additional lysine (K) on the C-terminus (Table 1). An additional two peptides, LF-3 and LF-4 contained extended sequences based on the consensus.

MALDI-TOF MS monitored the LF hydrolysis of all four peptides (LF-1 to LF-4) over time and their products were quantified as described previously (Figure 6) [7]. MALDI-TOF MS spectra after 2 hours reaction time with $10 \mathrm{ng}$ LF are shown for each peptide substrate. As expected only the NT peak was visible for LF-1 at $946.5 \mathrm{~m} / \mathrm{z}$. Both NT and CT products at 946.5 and $951.5 \mathrm{~m} / \mathrm{z}$ were visible in LF-2, due to the addition of the single lysine to the C-terminus of LF-1 (Figure 6B). This is clearly seen in the spectrum inset which focuses within a reduced mass window on both products. With the inset spectrum it can also be seen that the CT product of LF-2 has much lower intensity compared to the NT product due to the single ionizable amino acid in the CT product compared to four ionizable amino acids in the NT product (Figure 6B). LF-1 and LF-2 also have very low product intensities and very high substrate intensities (Figure 6A, B). In contrast, with the longer substrates, LF-3 and LF-4, the pattern is reversed with lower substrate intensities and higher product peak intensities, indicating greater substrate hydrolysis (Figure 6C, D).

The relative cleavage rates of these four substrates were determined by measuring the accumulation of hydrolysis products over time as previously described [7]. Briefly, the area ratios of the NT products for each peptide to an internal standard peptide (NT4-IS) were plotted versus reaction time (Figure 3E). NT4-IS is an isotopically labeled synthetic peptide that is 7 mass units higher than and with the same sequence as the LF-4 NT product, NT4 (Table 1). Accumulation of the NT hydrolysis products of the shorter peptides LF-1 and -2 was gradual out to 2 hours, after which no additional accumulation was observed (Figure 6E). In contrast, accumulation of NT products of LF-3 and LF-4 was faster and continued out to 4 hours. This substrate comparison suggests that the longer sequences were better substrates for LF since the hydrolysis products continued to accumulate over the 4 hour incubation. Greater product accumulation resulted in better sensitivity and detection limits.

In our current method we made an additional sequence substitution to improve the overall MS quantification. We substituted a norleucine $(\mathrm{X})$ for the methionine in the CT product of LF-4 yielding peptide substrate LF-5 (Table 1). Methionines are easily oxidized; thus at very high levels of LF we observed a low-intensity peak representing the oxidized form of the LF-4 CT product, CT-4 $(1,607.8+16 \mathrm{~m} / \mathrm{z})$. This $1,623.8 \mathrm{~m} / \mathrm{z}$ peak represents the displacement of a small portion of CT4 from the quantitative $1,607.8 \mathrm{~m} / \mathrm{z}$ peak. The simple substitution removed the opportunity for methionine oxidation. Thus, the total amount of product in the new substrate LF-5 was observed in the CT5 peak at $1,589.8 \mathrm{~m} / \mathrm{z}$, which is the main quantitative ion for the LF method. LF-5 had similar cleavage efficiency to LF-3 and -4 (data not shown). In all, the longer substrates were shown to be much better targets for LF hydrolysis. The same was observed for the botulinum neurotoxins and lengthened 
peptide substrates yielded higher amounts of cleavage products and lower detection limits (data not shown).

Figure 6. Comparison of cleavage efficiencies of lethal factor (LF) for various substrate peptides. Four peptides, LF-1, -2, -3, and -4, designed as potential substrates for LF, were compared to determine substrate qualities that produce enhanced LF hydrolysis. Full and expected LF cleaved peptide sequences and masses are shown for each substrate. Hydrolysis reactions for each substrate were conducted using $10 \mathrm{ng}$ of LF, with $5 \mathrm{nmol}$ of substrate in $200 \mu \mathrm{L}$ reaction buffer, incubated for $2 \mathrm{~h}$ at $37^{\circ} \mathrm{C}$ after which MALDI-TOF mass spectra were acquired without internal standard (A-D). The $\mathrm{X}$-axis was narrowed to visualize both hydrolysis products for LF-2 which were separated by 5 mass units. The relative rates of LF hydrolysis of these substrates were compared for all 4 substrates (E) with timed reaction for each in $200 \mu \mathrm{L}$ buffer and $10 \mathrm{ng} \mathrm{LF}, 5 \mathrm{nmol}$ substrate, at $37{ }^{\circ} \mathrm{C}$. MALDI-TOF mass spectra were acquired with internal standard (NT4-IS) at 5, 10, 15, 30, $45,60,90,120$, and $240 \mathrm{~min}$. The area ratio of the NT to NT4-IS peptide peaks was plotted for each peptide and time point and fitted to a quadratic equation that depicted the relative rates of reaction for each substrate $(\mathrm{E})$. The $\mathrm{X}$-axis was narrowed for a representative spectrum from the LF hydrolysis of LF-4 at 15 min showing the NT-4 and NT4-IS peaks.
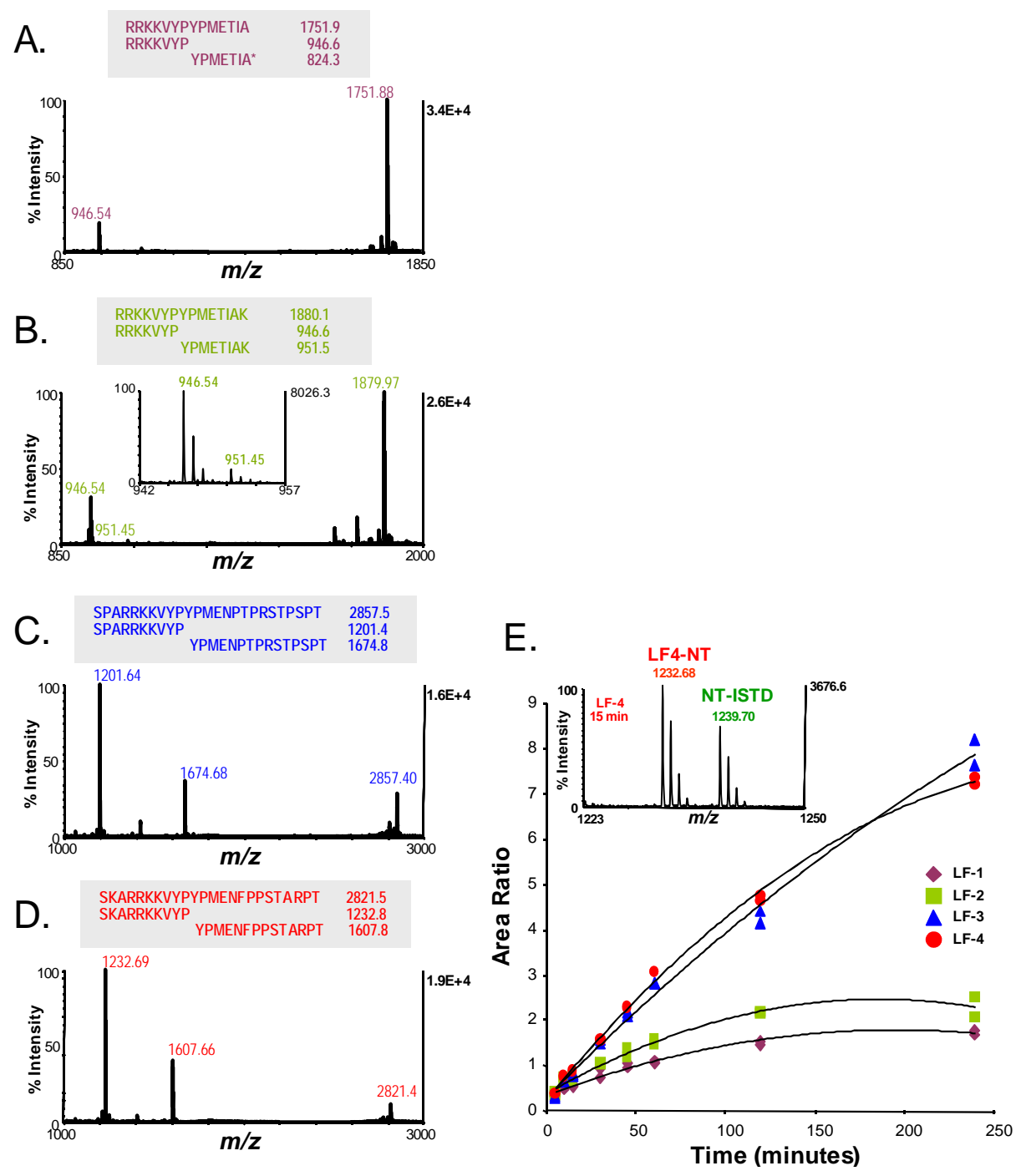


\subsection{Substrate design for other toxin activities}

Substrate design for other enzyme toxins depended on the catalytic properties. For example, substrate design and optimization was straightforward for the calmodulin-dependent adenylyl cyclase toxins including $B$. anthracis $\mathrm{EF}$ and the $B$. pertussis adenylyl cyclase (PAC) for which adenosine triphosphate (ATP) is considered the optimal substrate. It is likely that changes would reduce catalytic efficiency. For example, in our laboratory guanine triphosphate (GTP) was an inferior substrate (data not shown) and was demonstrated previously [34] indicating that a simple base change reduced the catalytic efficiency of EF.

Clostridium difficile has emerged as an important pathogen; it causes toxin-mediated illnesses ranging from mild diarrhea to fulminant pseudomembranous colitis in patients undergoing antimicrobial treatment and is the leading cause of hospital-associated diarrhea [35]. C. difficile toxins contributing to virulence include the glucosylating toxins, TcdA and TcdB, also known as Toxins A and B [36]. The toxin potency depends on their glucosyltransferase activity. Therefore, quantification of this activity in various strains associated with disease would be beneficial. The known substrates of TcdA and B include the small GTPases, Rho, Rac, and Cdc42, which are inactivated upon glucosylation of a threonine in position 37 in RhoA and 35 in Rac and Cdc42 [35]. It may be challenging to optimize substrates for MS detection of Tcd toxin activity as substrate specificity has only been shown for its full length GTPase polypeptides, which are not favorable for sensitive MS detection. We are investigating shorter peptides based on Rho, Rac and Cdc42 that include the Thr37/35 as possible substrates for glucosylation and MS detection.

\section{Enzyme Reaction Optimization}

\subsection{Reaction buffer optimization of endoprotease/peptide substrate reactions}

Optimization of conditions for the enzymatic reaction usually requires a standard buffer and mixture of metal ions. Hepes buffer at $\mathrm{pH}$ 7-8 was suitable for the enzyme reaction-based methods that were developed for LF, EF, and BoNTs [3,4,7,37]. However, for any enzyme, consideration of the reaction requirements including cofactors is essential. For the zinc-dependent endoproteases optimization of zinc $\left(\mathrm{Zn}^{2+}\right)$ concentration is important and divalent ions, $\mathrm{Ca}^{2+}, \mathrm{Mg}^{2+}$ and/or $\mathrm{Mn}^{2+}$ may be important as well. The optimal reaction buffer composition for LF was $20 \mathrm{mM}$ Hepes buffer $\mathrm{pH}$ 7.3., $1 \mathrm{mM}$ DTT, $20 \mu \mathrm{M} \mathrm{CaCl}_{2}, 10 \mathrm{mM} \mathrm{MgCl}, 20 \mu \mathrm{M} \mathrm{ZnCl}_{2}$ [7]. In contrast, additional divalent metal cations $\mathrm{CaCl}_{2}$ and $\mathrm{MgCl}_{2}$ did not enhance BoNT activity, whereas bovine serum albumin (BSA) was important for catalytic efficiency of BoNTs in the absence of antibody capture [3].

For the LF and BoNT endoprotease peptide cleavage reactions, protease inhibitors were also required to maintain peptide substrate stability. This was especially important when analyzing clinical samples such as stool, for BoNT analysis, or whole blood for LF analysis. These samples contain abundant endogenous cysteine- and serine-proteases that can contribute to non-specific degradation of the substrate peptide (Figure 3A). Even with prior toxin purification some proteases may remain. Therefore, optimization and selection of protease inhibitors was critical. For evaluation, we selected protease inhibitors that did not inhibit the toxin activity. For metal ion-dependent hydrolytic enzymes, metal chelators such as ethylene diamine tetraacetic acid (EDTA) were not used, since even low 
concentrations exhibited a negative impact on EF and BoNT catalytic activity. Protease inhibitors and concentrations optimized for LF and BoNT reaction buffers included $0.56 \mathrm{mg} / \mathrm{mL}$ 4-(2-aminoethyl) benzenesulfonyl fluoride hydrochloride (AEBSF), $3.125 \mathrm{mg} / \mathrm{mL} 6$-aminohexanoic acid, $0.3125 \mathrm{mg} / \mathrm{mL}$ antipain, $22 \mu \mathrm{g} / \mathrm{mL}$ (2S,3S)-trans-epoxysuccinyl-L-leucylamido-3-methylbutane ethyl ester (E-64D), and $0.125 \mathrm{mg} / \mathrm{mL}$ casein.

\subsection{Reaction buffer optimization of adenylate cyclase activities}

For the calcium and calmodulin dependent adenylyl cyclase family, which includes EF and PAC, reaction buffer optimization was completed using the JMP Statistical Discovery software 'Design of Experiments' protocol (JMP, Cary, NC) and yielded an optimal buffer formulation of $20 \mathrm{mM}$ Hepes, pH 7.3, $0.1 \mathrm{mg} / \mathrm{mL}$ BSA, $1 \mathrm{mM}$ EDTA, $10 \mathrm{mM} \mathrm{CaCl}_{2}, 43 \mathrm{mM} \mathrm{MgCl}, 1 \mu \mathrm{M}$ calmodulin, and $0.05 \mathrm{mM}$ ATP [29].

Figure 7. Mouse mAb's, polyclonal serum (pAb) from rabbit immunized with LF, and $\mathrm{pAb}$ from rhesus macaque immunized with LF were covalently linked to protein $\mathrm{G}$ magnetic beads according to the manufacturer's instructions (Invitrogen, Carlsbad, CA). All three antibodies on beads were used to capture $1 \mathrm{ng}$ LF from serum, react with substrate LF-4 for $1.5 \mathrm{~h}$, and MALDI-TOF MS was acquired according to procedures previously described [7]. The full mass spectrum is shown for the mouse LF mAb (A). MS focused on the CT4 LF cleavage product are shown for the mouse LF mAb (B), rabbit LF $\mathrm{pAb}(\mathrm{C})$, and macaque LF pAb (D).

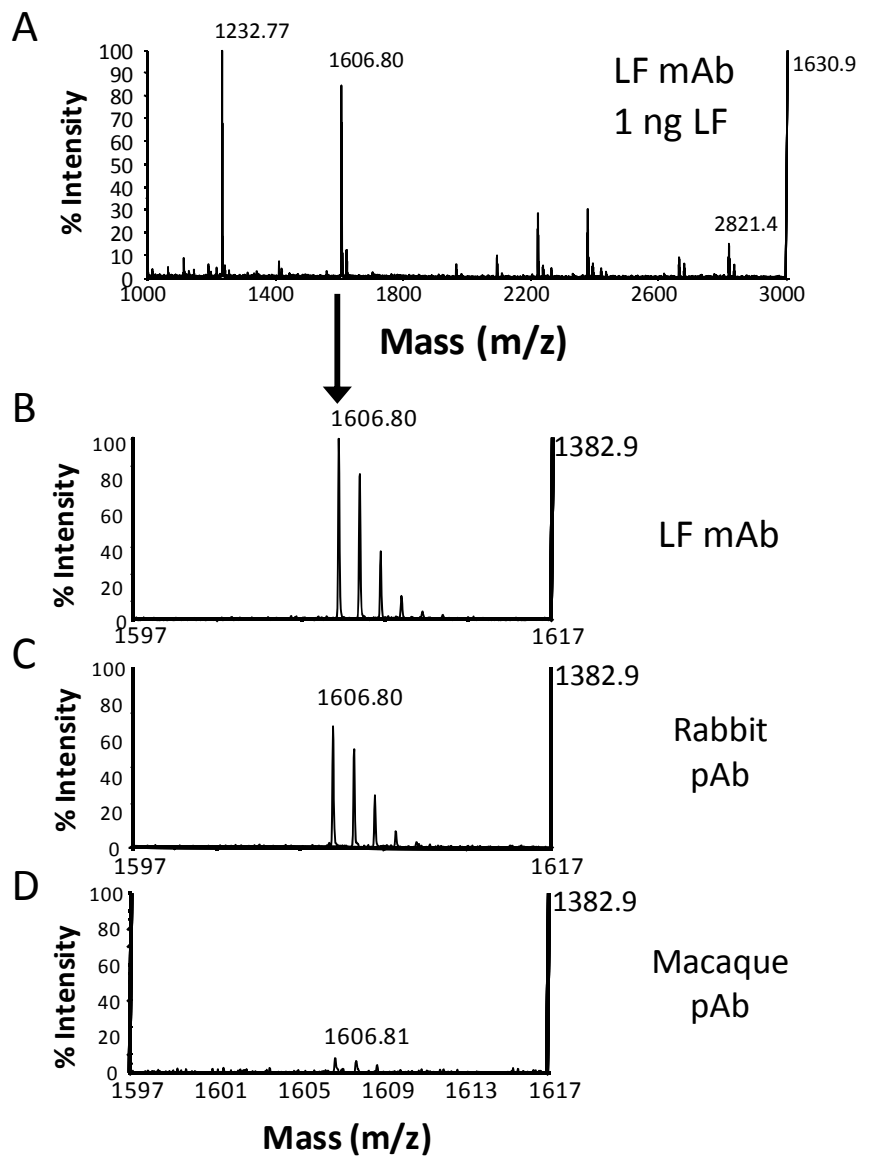




\section{Toxin Purification and Enrichment}

The base of our toxin detection methods includes toxin concentration and purification using monoclonal antibodies (mAbs) crosslinked to Protein $G$ or tosyl-activated magnetic beads. The magnetic bead extraction protocol resulted in significantly enhanced cleavage reactivity compared to crosslinking and capturing LF directly on a microtiter plate as is performed with typical enzyme-linked immunosorbent assays (ELISA). In the magnetic bead format there may be more steric freedom for interaction between antibody and toxin, and subsequent catalytic reactions. Magnetic beads, also provide an increased surface area for antibody loading on the bead, resulting in higher LF capture capacity.

Antibody selection for optimal toxin capture is another important criterion for method development. Although polyclonal antibodies (pAbs) are potentially useful, the myriad of possible epitopes they could recognize increases the probability that they will bind at or near the catalytic sight and interfere with the subsequent enzymatic reaction. For example, we compared the capture of $1 \mathrm{ng}$ of LF using the LF mAb, polyclonal rabbit antisera to LF, and polyclonal rhesus macaque antisera to LF (Figure 7). Figure 7A shows the full MALDI-TOF MS from a 1.5 hour reaction of substrate LF-4 with LF captured by the LF mAb. In the spectrum focused on CT4, we observed a much greater accumulation of product from LF reactivity after capture by the LF mAb, a little less with the rabbit pAb, and very little product with the macaque pAb (Figure 7B-D). This indicates that the rhesus antisera had high toxin-neutralizing activity. For use in the final method, we selected two LF mAbs with no neutralizing activity, one of which was included in Figure 7A-B [38].

\section{Toxin Quantification}

The method development steps, toxin capture, catalytic reactivity, and mass spectrometry, combined, provide enhanced sensitivity and specificity compared to other diagnostic methods such as ELISA [39,40]. Incorporation of isotope dilution mass spectrometry also provides the ability to quantify toxin activity with a high degree of precision and accuracy. Coefficients of variation for LF quality control samples for 28 independent runs was $8.5-14.7 \%$ and accuracy for LF spiked samples ranged from 86 to $98.8 \%$ [38]. Serum or plasma standards were created by spiking recombinant LF at concentrations in the pre-optimized range. The spiked standards are subject to magnetic LF antibody bead capture, substrate cleavage reaction, and MALDI-TOF MS as described previously [6,7]. Concentrations optimized for LF using $20 \mu \mathrm{L}$ of sample and 2 hour reaction incubation ranges from 0.125-25 ng/mL LF [38]. Extending the reaction overnight for the $20 \mu \mathrm{L}$ sample volume yields an optimal quantifiable concentration curve range of $0.025-10 \mathrm{ng} / \mathrm{mL}$ (Figure $8 \mathrm{~A}$ ). Using a larger sample and standard volume, $200 \mu \mathrm{L}$, provides a similar concentration range and sensitivity of $0.025-10 \mathrm{ng} / \mathrm{mL}$, in the shorter $2 \mathrm{~h}$ time period. Continuing the $200 \mu \mathrm{L}$ reaction overnight yields an optimal range of $0.005-1 \mathrm{ng} / \mathrm{mL}$. The lowest three standards and plasma blank are shown for the $200 \mu \mathrm{L} 2 \mathrm{~h}$ reaction (Figure 8B) and continued overnight reaction (Figure 8C). These spectra show the rapid, less than 4 hour time to detection limit of $0.025 \mathrm{ng} / \mathrm{mL}$ and the detection limit for the extended reaction time of $0.005 \mathrm{ng} / \mathrm{mL}$ (Figure $8 \mathrm{~B}, \mathrm{C}$ ).

Custom in-house designed Visual Basic programs allow conversion of the MALDI-TOF T2Dgenerated mass spectra to text files. These text files are then manipulated to sum the isotopes and 
produce a single chromatogram peak format for peak area determination. Area ratios of the target CT-5 analyte peak to CT5-IS are plotted versus the LF concentration on a $\log _{10}-\log _{10}$ scale. The standard curves generated are primarily linear in the central range and deviate slightly at the upper and lower bounds. Therefore, a 4-point sliding linear fit is incorporated which is stitched (Figure 8A) and algorithms are used to calculate unknown sample values. LF quantification has been validated independently on both the MALDI-TOF MS and LC-ESI-MS/MS platforms and also cross-validated between instruments by analyzing the same standard sets and unknowns [28]. As discussed earlier, this cross-validation verified a close agreement between the two different MS platforms.

Figure 8. Standard curve for the low volume $(20 \mu \mathrm{L})$ overnight incubation for standards ranging from $0.025 \mathrm{ng} / \mathrm{mL}$ to $10 \mathrm{ng} / \mathrm{mL} \mathrm{LF}$ spiked in plasma, captured by LF mAbs on magnetic beads, and incubated with substrate LF-5, analyzed by MALDI-TOF MS, and CT-5 peaks quantified as described previously[6,7] (A). Spectra are shown with the X-axis narrowed on CT-5 LF hydrolysis product peak for high volume $(200 \mu \mathrm{L})$ of LF standards; $0.125 \mathrm{ng} / \mathrm{mL}, 0.05 \mathrm{ng} / \mathrm{mL}, 0.025 \mathrm{ng} / \mathrm{mL}$, and plasma blank control for $2 \mathrm{~h}$ reaction (B) and for $0.0125 \mathrm{ng} / \mathrm{mL}, 0.0075 \mathrm{ng} / \mathrm{mL}$, and $0.005 \mathrm{ng} / \mathrm{mL}$ for the extended incubation $(\mathrm{C})$.
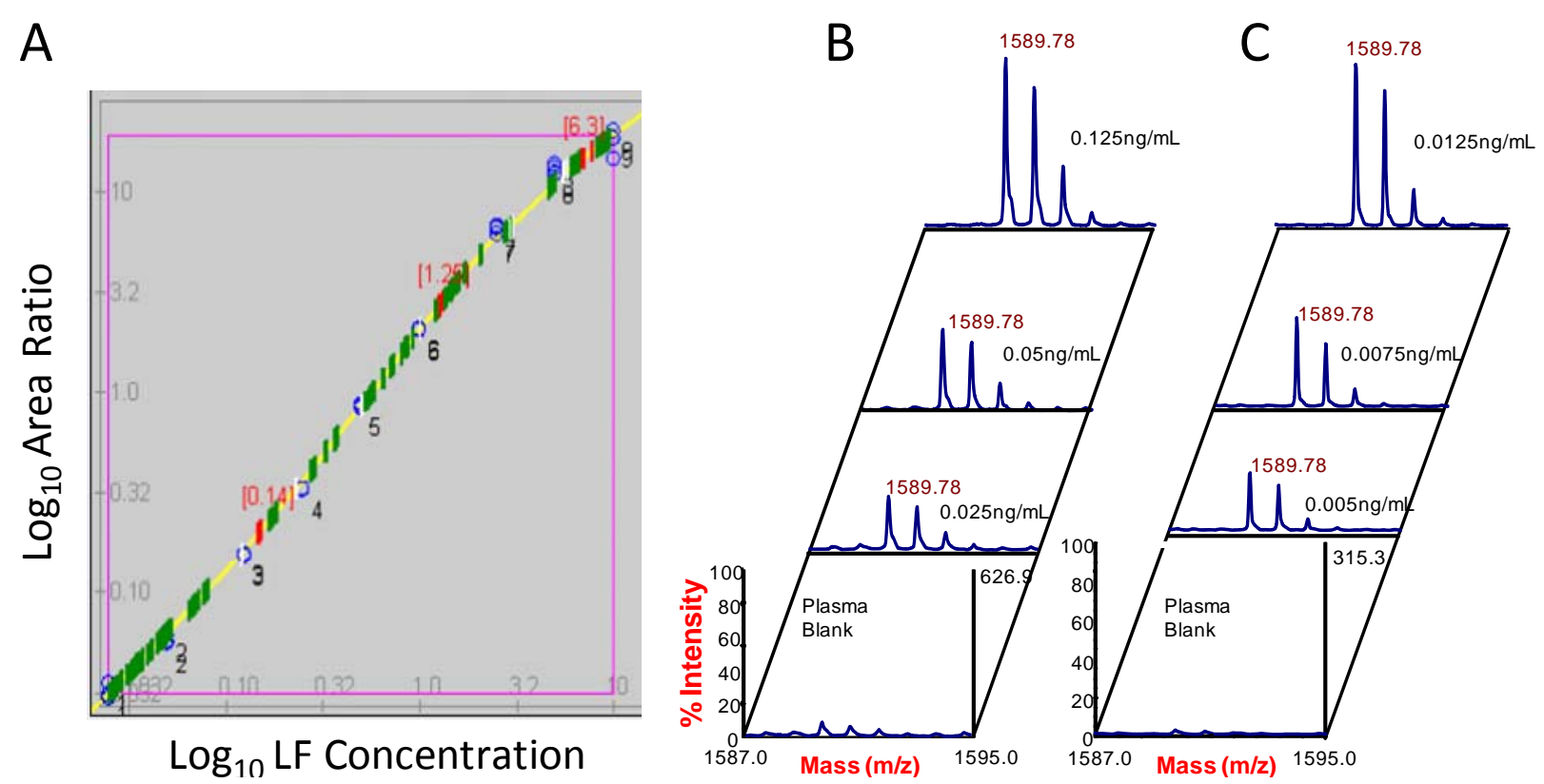

\section{Discussion}

These activity-based MS analyses have yielded advanced detection methods for diagnosis and detection of anthrax toxins and botulinum neurotoxins with detection limits at $5 \mathrm{pg} / \mathrm{mL}$ for LF and as low as 0.05 mouse LD50 for BoNT's [41], up to 20 times greater analytic sensitivity than the mouse bioassay. The $5 \mathrm{pg} / \mathrm{mL}$ detection limit for LF ranges from 2-4,000 times better than detection limits for other recently developed methods for anthrax toxins which range from $0.01-20 \mathrm{ng} / \mathrm{mL}[39,40,42]$. The ultra-low detection limits for the LF MS method has facilitated LF detection and diagnosis in early infection, as early as $12 \mathrm{~h}$ after spore exposure in both rabbits and rhesus macaques with anthrax $[21,43]$. For previously developed methods, anthrax toxins PA and LF, have only been measured in late infection, even with a PA method with fairly low detection limits [42]. The LF method also has excellent precision and accuracy, as described above. The EF method detection limit is almost 1000 
times lower than that for LF (manuscript in preparation) and therefore, might detect toxin earlier after exposure than observed for the LF method.

The measurement of LF in rhesus macaques with inhalation anthrax provided the first report of a triphasic kinetics of toxemia. Measurement of LF also tracked the course of clinical treatment in a patient with advanced inhalation anthrax which suggests such measurements might be useful for evaluating the efficacy of anthrax therapeutics [22]. In support of its utility and effectiveness, the LF method has been included as part of the CDC response plan during an anthrax emergency. It is also a required measurement under the investigational new drug protocol for use of the anthrax anti-toxin, anthrax immune globulin intravenous (AIGIV).

The use of these methods for the BoNTs provides several distinct advantages over the mouse bioassay for diagnosis, toxin typing, and subtyping. For example, toxin detection can be multiplexed for detecting toxin types /A, /B, /C, /D, /E, and /F [3]. Multiplexing for the primary BoNT types that affect humans, /A, /B, /E, and /F only requires a maximum volume of $500 \mu \mathrm{L}$ of toxin-containing serum or food sample [41]. The BoNT in a sample, /A, /B, /E, and/or /F is purified with a single highaffinity antibody with specificity for a region that is homologous in all types /A, /B, /E and /F [41]. The captured BoNT is then reacted with four peptide substrates based on SNAP-25 and VAMP-2 that differentiate these four BoNT serotypes based on differential cleavage of any substrate [41]. For example, certain strains of $C$. botulinum produce more than one BoNT serotype (e.g., Ab, Ba, Af producing strains), which would cleave each of two peptide substrates in specific locations. This dual activity can be easily determined by the described methods in one reaction [41]. However, the mouse bioassay requires several milliliters of sample since it must use $500 \mu \mathrm{L}-1 \mathrm{~mL}$ for each individual mouse which will receive either no anti-toxin or individual anti-toxins to $\mathrm{A}, \mathrm{B}, \mathrm{E}$, and $\mathrm{F}$ to determine the type that protects the mouse from botulism. This does not take into account quantification of the BoNT levels. Additional mice and sample volumes are required for mouse $\mathrm{LD}_{50}$ quantification. Additional advantages to the MS methods include the ability to obtain detailed toxin type information. After antibody capture and the BoNT substrate cleavage reaction, the toxin captured on the beads can be digested with trypsin and sequenced for delivering information about the specific subtype and even identification of novel subtypes $[5,41,44]$. The BoNT methods also provide enhanced sensitivity over the mouse for all toxin types. This provides an excellent resource for rapid BoNT detection and toxintyping during an emergency related to intentional or accidental C. botulinum contamination of food or other consumables [45].

We are developing similar toxin activity based methods for Clostridium difficile and Bordetella pertussis, both of which have gained or regained prominence in recent years as important pathogens causing public health problems. C. difficile has developed enhanced virulence and currently only two anti-infectives, metronidazole and vancomycin, are routinely used to treat it [46]. It has been suggested that treatment with fluoroquinolones for other infections may predispose patients to $C$. difficile infection by eliminating the protective intestinal flora [47]. For B. pertussis, the re-emergence of infections reported since 1990 in areas with widespread vaccination [48] is presumed to be due to decreased effectiveness of the vaccine [49]. The cause has not been definitively identified but it may be due to shifts in genes for fimbriae and/or waning immunity in adolescents and adults [50]. Methods quantifying the activity of these toxins may be used to evaluate toxin vaccine responses and yield insights into increased virulence. 


\section{Conclusions}

The advanced capabilities, speed, and specificity of methods employing both the enzymatic properties of toxins combined with mass spectrometric detection have advanced what we now understand about anthrax infection [6] and botulinum neurotoxins [51]. Application of these methods to toxin quantification for other infections and intoxications may yield novel insights into these emerging public health concerns. Methods which can quantify toxins associated with these pathogens, as well as those causing anthrax and botulism, may provide enhanced diagnostic tests, help understand the nature of changes leading to enhanced virulence, pathogenicity, losses in vaccine efficacy, and provide an accurate measure for evaluating the efficacy of novel therapeutics and vaccines.

\section{References}

1. Rossetto, O.; de Bernard, M.; Pellizzari, R.; Vitale, G.; Caccin, P.; Schiavo, G.; Montecucco, C. Bacterial toxins with intracellular protease activity. Clin. Chim. Acta 2000, 291, 189-199.

2. Tournier, J.N.; Quesnel-Hellmann, A.; Cleret, A.; Vidal, D.R. Contribution of toxins to the pathogenesis of inhalational anthrax. Cell Microbiol. 2007, 9, 555-565.

3. Boyer, A.E.; Moura, H.; Woolfitt, A.R.; Kalb, S.R.; McWilliams, L.G.; Pavlopoulos, A.; Schmidt, J.G.; Ashley, D.L.; Barr, J.R. From the mouse to the mass spectrometer: detection and differentiation of the endoproteinase activities of botulinum neurotoxins A-G by mass spectrometry. Anal. Chem. 2005, 77, 3916-3924.

4. Kalb, S.R.; Moura, H.; Boyer, A.E.; McWilliams, L.G.; Pirkle, J.L.; Barr, J.R. The use of Endopep-MS for the detection of botulinum toxins A, B, E, and F in serum and stool samples. Anal. Biochem. 2006, 351, 84-92.

5. Kalb, S.R.; Lou, J.; Garcia-Rodriguez, C.; Geren, I.N.; Smith, T.J.; Moura, H.; Marks, J.D.; Smith, L.A.; Pirkle, J.L.; Barr, J.R. Extraction and inhibition of enzymatic activity of botulinum neurotoxins/A1, /A2, and /A3 by a panel of monoclonal anti-BoNT/A antibodies. PLoS One 2009, 4, e5355.

6. Boyer, A.E.; Quinn, C.P.; Hoffmaster, A.R.; Kozel, T.R.; Saile, E.; Marston, C.K.; Percival, A.; Plikaytis, B.D.; Woolfitt, A.R.; Gallegos, M.; Sabourin, P.; McWilliams, L.G.; Pirkle, J.L.; Barr, J.R. Kinetics of lethal factor and poly-D-glutamic acid antigenemia during inhalation anthrax in rhesus macaques. Infect. Immun. 2009, 77, 3432-3441.

7. Boyer, A.E.; Quinn, C.P.; Woolfitt, A.R.; Pirkle, J.L.; McWilliams, L.G.; Stamey, K.L.; Bagarozzi, D.A.; Hart, J.C., Jr.; Barr, J.R. Detection and quantification of anthrax lethal factor in serum by mass spectrometry. Anal. Chem. 2007, 79, 8463-8470.

8. Pellizzari, R.; Rossetto, O.; Schiavo, G.; Montecucco, C. Tetanus and botulinum neurotoxins: mechanism of action and therapeutic uses. Philos. Trans. R. Soc. Lond. B Biol. Sci. 1999, 354, 259-268.

9. Hill, K.K.; Smith, T.J.; Helma, C.H.; Ticknor, L.O.; Foley, B.T.; Svensson, R.T.; Brown, J.L.; Johnson, E.A.; Smith, L.A.; Okinaka, R.T.; Jackson, P.J.; Marks, J.D. Genetic diversity among Botulinum Neurotoxin-producing clostridial strains. J. Bacteriol. 2007, 189, 818-832.

10. Schiavo, G.; Matteoli, M.; Montecucco, C. Neurotoxins affecting neuroexocytosis. Physiol. Rev. 2000, 80, 717-766. 
11. Moriishi, K.; Koura, M.; Abe, N.; Fujii, N.; Fujinaga, Y.; Inoue, K.; Ogumad, K. Mosaic structures of neurotoxins produced from Clostridium botulinum types $\mathrm{C}$ and $\mathrm{D}$ organisms. Biochim. Biophys. Acta 1996, 1307, 123-126.

12. Moura, H.T.R.; Woolfitt, A.R.; Gallegos-Candela, M.; McWilliams, L.G.; Solano, M.I.; Pirkle, J.L.; Barr, J.R. Studies on Botulinum Neurotoxins Type /C1 and mosaic /DC Using Endopep-MS and Proteomics. FEMS Immunol. Microbiol. 2011, in press.

13. Smith, T.J.; Lou, J.; Geren, I.N.; Forsyth, C.M.; Tsai, R.; Laporte, S.L.; Tepp, W.H.; Bradshaw, M.; Johnson, E.A.; Smith, L.A.; Marks, J.D. Sequence variation within botulinum neurotoxin serotypes impacts antibody binding and neutralization. Infect. Immun. 2005, 73, 5450-5457.

14. Mock, M.; Mignot, T. Anthrax toxins and the host: A story of intimacy. Cell Microbiol. 2003, 5, 15-23.

15. Turk, B.E. Manipulation of host signalling pathways by anthrax toxins. Biochem. J. 2007, 402, 405-417.

16. Klimpel, K.R.; Molloy, S.S.; Thomas, G.; Leppla, S.H. Anthrax toxin protective antigen is activated by a cell surface protease with the sequence specificity and catalytic properties of furin. Proc. Natl. Acad. Sci. USA 1992, 89, 10277-10281.

17. Molloy, S.S.; Bresnahan, P.A.; Leppla, S.H.; Klimpel, K.R.; Thomas, G. Human furin is a calcium-dependent serine endoprotease that recognizes the sequence Arg-X-X-Arg and efficiently cleaves anthrax toxin protective antigen. J. Biol. Chem. 1992, 267, 16396-16402.

18. Kintzer, A.F.; Thoren, K.L.; Sterling, H.J.; Dong, K.C.; Feld, G.K.; Tang, II; Zhang, T.T.; Williams, E.R.; Berger, J.M.; Krantz, B.A. The protective antigen component of anthrax toxin forms functional octameric complexes. J. Mol. Biol. 2009, 392, 614-629.

19. Warfel, J.M.; Steele, A.D.; D'Agnillo, F. Anthrax lethal toxin induces endothelial barrier dysfunction. Am. J. Pathol. 2005, 166, 1871-1881.

20. Sweeney, D.A.; Cui, X.; Solomon, S.B.; Vitberg, D.A.; Migone, T.S.; Scher, D.; Danner, R.L.; Natanson, C.; Subramanian, G.M.; Eichacker, P.Q. Anthrax lethal and edema toxins produce different patterns of cardiovascular and renal dysfunction and synergistically decrease survival in canines. J. Infect. Dis. 2010, 202, 1885-1896.

21. Boyer, A.E.; Quinn, C.P.; Hoffmaster, A.R.; Kozel, T.; Gallegos, M.; Saile, E.; Marston, C.; Beesley, C.; Percival, A.; Lins, R.; Woolfitt, A.; Pirkle, J.L.; Barr, J.R. Association of Early Lethal Factor Levels with Survival during Inhalation Anthrax in Rhesus Macaques. In Proceedings of ASM Biodefense and Emerging Diseases Research Meeting, Baltimore, MD, USA, 6-9 February 2010; American Society for Microbiology: Washington, DC, USA, 2010.

22. Walsh, J.J.; Pesik, N.; Quinn, C.P.; Urdaneta, V.; Dykewicz, C.A.; Boyer, A.E.; Guarner, J.; Wilkins, P.; Norville, K.J.; Barr, J.R.; Zaki, S.R.; Patel, J.B.; Reagan, S.P.; Pirkle, J.L.; Treadwell, T.A.; Messonnier, N.R.; Rotz, L.D.; Meyer, R.F.; Stephens, D.S. A case of naturally acquired inhalation anthrax: Clinical care and analyses of anti-protective antigen immunoglobulin $\mathrm{G}$ and lethal factor. Clin. Infect. Dis. 2007, 44, 968-971.

23. Ferreira, J.L.; Maslanka, S.; Johnson, E.; Goodnough, M. Detection of botulinal neurotoxins A, B, $\mathrm{E}$, and $\mathrm{F}$ by amplified enzyme-linked immunosorbent assay: Collaborative study. J. AOAC Int. 2003, 86, 314-331. 
24. Ezzell, J.W., Jr.; Abshire, T.G. Serum protease cleavage of Bacillus anthracis protective antigen. J. Gen. Microbiol. 1992, 138, 543-549.

25. Panchal, R.G.; Halverson, K.M.; Ribot, W.; Lane, D.; Kenny, T.; Abshire, T.G.; Ezzell, J.W.; Hoover, T.A.; Powell, B.; Little, S.; Kasianowicz, J.J.; Bavari, S. Purified Bacillus anthracis lethal toxin complex formed in vitro and during infection exhibits functional and biological activity. $J$. Biol. Chem. 2005, 280, 10834-10839.

26. Barr, J.R.; Maggio, V.L.; Patterson, D.G., Jr.; Cooper, G.R.; Henderson, L.O.; Turner, W.E.; Smith, S.J.; Hannon, W.H.; Needham, L.L.; Sampson, E.J. Isotope dilution--mass spectrometric quantification of specific proteins: model application with apolipoprotein A-I. Clin. Chem. 1996, 42, 1676-1682.

27. Williams, T.L.; Luna, L.; Guo, Z.; Cox, N.J.; Pirkle, J.L.; Donis, R.O.; Barr, J.R. Quantification of influenza virus hemagglutinins in complex mixtures using isotope dilution tandem mass spectrometry. Vaccine 2008, 26, 2510-2520.

28. Kuklenyik, Z.; Boyer, A.E.; Lins, R.; Quinn, C.P.; Gallegos-Candela, M.; Woolfitt, A.R.; Pirkle, J.L.; Barr, J.R. Comparison of MALDI-TOF-MS and HPLC-ESI-MS/MS for Endopeptidase Activity Based Quantification of Anthrax Lethal Factor in Serum. Anal. Chem. 2011, in press.

29. Lins, R.C.; Boyer, A.E.; Kuklenyik, Z.; Quinn, C.P.; Gallegos-Candela, M.; Leysath, C.E.; Chen, Z.; Chen, K.; Makiya, M.; Leppla, S.H.; Pirkle, J.L.; Barr, J.R. In A High Sensitivity Adenylate Cyclase Assay for Anthrax Edema factor., Proceedings of 58th ASMS Conference on Mass Spectrometry and Allied Topics, Salt Lake City, UT, USA, 23-27 May 2010; American Society for Mass Spectrometry: Santa Fe, NM, USA, 2010.

30. Turk, B.E.; Wong, T.Y.; Schwarzenbacher, R.; Jarrell, E.T.; Leppla, S.H.; Collier, R.J.; Liddington, R.C.; Cantley, L.C. The structural basis for substrate and inhibitor selectivity of the anthrax lethal factor. Nat. Struct. Mol. Biol. 2004, 11, 60-66.

31. Pellizzari, R.; Guidi-Rontani, C.; Vitale, G.; Mock, M.; Montecucco, C. Anthrax lethal factor cleaves MKK3 in macrophages and inhibits the LPS/IFNgamma-induced release of NO and TNFalpha. FEBS Lett. 1999, 462, 199-204.

32. Duesbery, N.S.; Webb, C.P.; Leppla, S.H.; Gordon, V.M.; Klimpel, K.R.; Copeland, T.D.; Ahn, N.G.; Oskarsson, M.K.; Fukasawa, K.; Paull, K.D.; Vande Woude, G.F. Proteolytic inactivation of MAP-kinase-kinase by anthrax lethal factor. Science 1998, 280, 734-737.

33. Vitale, G.; Bernardi, L.; Napolitani, G.; Mock, M.; Montecucco, C. Susceptibility of mitogenactivated protein kinase kinase family members to proteolysis by anthrax lethal factor. Biochem. $J$. 2000, 352 (Pt. 3), 739-745.

34. Guo, Q.; Shen, Y.; Zhukovskaya, N.L.; Florian, J.; Tang, W.J. Structural and kinetic analyses of the interaction of anthrax adenylyl cyclase toxin with reaction products cAMP and pyrophosphate. J. Biol. Chem. 2004, 279, 29427-29435.

35. Voth, D.E.; Ballard, J.D. Clostridium difficile toxins: Mechanism of action and role in disease. Clin. Microbiol. Rev. 2005, 18, 247-263.

36. Jank, T.; Giesemann, T.; Aktories, K. Rho-glucosylating Clostridium difficile toxins A and B: new insights into structure and function. Glycobiology 2007, 17, 15R-22R.

37. Leppla, S.H. Anthrax toxin edema factor: A bacterial adenylate cyclase that increases cyclic AMP concentrations of eukaryotic cells. Proc. Natl. Acad. Sci. USA 1982, 79, 3162-3166. 
38. Gallegos-Candela, M.; Boyer, A.E.; Quinn, C.P.; Woolfitt, A.R.; Barr, J.R. Validation of Rapid, Sensitive, Quantitative MALDI-TOF MS Assays for Anthrax Lethal Factor and Lethal Toxin, Bacillus-ACT 2009. In Proceedings of the International Bacillus Anthracis, B. Cereus, and B. Thuringiensis Conference, Santa Fe, NM, USA, 30 August-3 September, 2009; American Society for Microbiology: Washington, DC, USA, 2009.

39. Kobiler, D.; Weiss, S.; Levy, H.; Fisher, M.; Mechaly, A.; Pass, A.; Altboum, Z. Protective antigen as a correlative marker for anthrax in animal models. Infect. Immun. 2006, 74, 5871-5876.

40. Mabry, R.; Brasky, K.; Geiger, R.; Carrion, R., Jr.; Hubbard, G.B.; Leppla, S.; Patterson, J.L.; Georgiou, G.; Iverson, B.L. Detection of anthrax toxin in the serum of animals infected with Bacillus anthracis by using engineered immunoassays. Clin. Vaccine Immunol. 2006, 13, 671-677.

41. Kalb, S.R.; Garcia-Rodriguez, C.; Lou, J.; Baudys, J.; Smith, T.J.; Marks, J.D.; Smith, L.A.; Pirkle, J.L.; Barr, J.R. Extraction of BoNT/A, /B, /E, and /F with a single, high affinity monoclonal antibody for detection of botulinum neurotoxin by Endopep-MS. PLoS One 2010, 5, e12237.

42. Tang, S.; Moayeri, M.; Chen, Z.; Harma, H.; Zhao, J.; Hu, H.; Purcell, R.H.; Leppla, S.H.; Hewlett, I.K. Detection of anthrax toxin by an ultrasensitive immunoassay using europium nanoparticles. Clin. Vaccine Immunol. 2009, 16, 408-413.

43. Boyer, A.E.; Quinn, C.P.; Hoffmaster, A.; Gallegos, M.; Saile, E.; Marston, C.; Kozel, T.; Meister, G.; Woolfitt, A.R.; Pirkle, J.L.; Barr, J.R. Kinetics of Toxemia of Inhalation Anthrax. In Proceedings of 6th Annual ASM Biodefense and Emerging Diseases Research Meeting, Baltimore, MD, USA, 24-27 February 2008; American Society for Microbiology: Washington, DC, USA, 2008.

44. Kalb, S.R.; Goodnough, M.C.; Malizio, C.J.; Pirkle, J.L.; Barr, J.R. Detection of botulinum neurotoxin A in a spiked milk sample with subtype identification through toxin proteomics. Anal. Chem. 2005, 77, 6140-6146.

45. Barr, J.R.; Kalb, S.R.; Moura, H.; Pirkle, J.L. Biological Monitoring of Exposure to Botulinum Neurotoxins. Chem. Health Safety 2008, 15, 14-19.

46. Belmares, J.; Gerding, D.N.; Tillotson, G.; Johnson, S. Measuring the severity of Clostridium difficile infection: implications for management and drug development. Expert Rev. Anti Infect. Ther. 2008, 6, 897-908.

47. Deshpande, A.; Pant, C.; Jain, A.; Fraser, T.G.; Rolston, D.D. Do fluoroquinolones predispose patients to Clostridium difficile associated disease? A review of the evidence. Curr. Med. Res. Opin. 2008, 24, 329-333.

48. Guris, D.; Strebel, P.M.; Bardenheier, B.; Brennan, M.; Tachdjian, R.; Finch, E.; Wharton, M.; Livengood, J.R. Changing epidemiology of pertussis in the United States: increasing reported incidence among adolescents and adults, 1990-1996. Clin. Infect. Dis. 1999, 28, 1230-1237.

49. King, A.J.; van Gorkom, T.; Pennings, J.L.; van der Heide, H.G.; He, Q.; Diavatopoulos, D.; Heuvelman, K.; van Gent, M.; van Leeuwen, K.; Mooi, F.R. Comparative genomic profiling of Dutch clinical Bordetella pertussis isolates using DNA microarrays: Identification of genes absent from epidemic strains. BMC Genomics 2008, 9, 311.

50. Godfroid, F.; Denoel, P.; Poolman, J. Are vaccination programs and isolate polymorphism linked to pertussis re-emergence? Expert Rev. Vaccines 2005, 4, 757-778. 
51. Kalb, S.R.; Baudys, J.; Egan, C.; Smith, T.J.; Smith, L.A.; Pirkle, J.L.; Barr, J.R. Clostridium baratii Type F Neurotoxin Cleaves Synaptobrevin-2 with Different Substrate Recognition Requirement than Clostridium botulinum Type F Neurotoxin. Appl. Environ. Microbiol. 2011, 77, 1301-1308.

Sample Availability: Samples of the compounds are commercially available. Anthrax toxins were acquired from List Biological Laboratories,USA and B. Pertussis adenylate cyclase toxins and ATP and cAMP are available from Sigma-Aldrich, USA.

(C) 2011 by the authors; licensee MDPI, Basel, Switzerland. This article is an open access article distributed under the terms and conditions of the Creative Commons Attribution license (http://creativecommons.org/licenses/by/3.0/). 